\title{
Pragmatic Functions of Crisis - Motivated Proverbs in Ola Rotimi's The Gods Are Not to Blame
}

\author{
Akin Odebunmi (Ibadan)
}

\begin{abstract}
The paper examines the pragmatic functions that crisis-motivated proverbs play in Ola Rotimi's The Gods is not to Blame. It picks its inspiration from the little attention hitherto paid, in the linguistic literature, to both the specific proverbs that are spurred by crisis in the play and the pragmatic roles of such proverbs. For data, only the proverbs that are necessitated by the crisis-situations in the text are sampled, and these are analysed, using the recent theory of pragmatic acts (Mey 2001).

The study reveals that crisis-motivated proverbs in The Gods are not to Blame, which are of two types: social and political, are characterized by practs such as those of counselling, cautioning, challenging, veiling, persuading, prioritizing, encouraging, threatening and admitting. These are psychological acts which exploit contextual features such as reference, metaphor, inference, shared situation knowledge, shared cultural knowledge and relevance. The paper concludes that studying literary proverbs used in crisis situations, from a pragmatic perspective, both throws additional insights into the paremiological pool and promises to provide a veritably helpful tool for language teaching.
\end{abstract}

\section{Introduction}

A large concentration of the studies on Ola Rotimi's The Gods are not to Blame, henceforth The Gods, come from the literary (e.g. Dasylva 2004) and sociological (e.g. Green/KoruboSolomon 2002) perspectives. Extremely little attempts have been made to carry out linguistic analyses of the text, when compared to other plays of the author. The reason for this relative neglect is, however, not the concern of this paper. Oloruntoba-Oju (1998) is a major study of Ola Rotimi's plays. It does a stylistic analysis of actional tradition in The Gods, Kurunmi and Ovonramwen Nogbaisi.

The fact is that it is rare to find a whole work devoted to the linguistic analysis of The Gods. The situation is worse with the use of proverbs in the text. Except Monye (1995) which analyses all the proverbs in the text, other studies such as Dairo (2001) and Ogbulogo (2002) merely mention the subject with reference to The Gods in their discussions of other works of Ola Rotimi. Monye (1995) restricts himself to broadly identifying the fifty-three proverbs in the play and discussing each in relation to the context in which it is used, without anchoring his analysis on any theoretical framework. This approach leaves a lot undone in a linguistic enterprise. We shall, therefore, in this paper, unlike Monye who does a broad analysis, classify the proverbs in The Gods and analyse them using Mey's (2001) theory of pragmatic acting. It is expected that this paper provide additional paremiological insights into the literature and help in language teaching.

The choice of The Gods has been informed, not only by the little attention paid to the use of proverbs in it, but also by the richness of its language, especially its faithful translation of 
Yoruba proverbs. For data, only the crisis-motivated proverbs (one of the classes of proverbs identified) in The Gods are selected and these are analysed through the theory of pragmatic acting.

\section{Language, Culture and Proverbs}

There is an intricate relationship between language and culture. This relationship is exhibited in terms of language being a part of culture, and yet being its vehicle. Culture is "the way of life for an entire society" (Jary and Jary 1991: 101), which means that aspects of human life such as codes of manners, dressing, religion, ritual norms, behaviour, belief systems and language are subsumed under culture. This large scope, which is outside the focus of this paper, has generated issues on the universalistic and relativistic dimensions of culture (cf. Khadka 2000).

Culture is lived, and language, through all its manifestations, projects that living, giving it form and texture. According to Leigh and Stanbridge (1991: 2), culture is:

A mixture which incorporates behaviour (thoughts, actions and language), knowledge, belief, art morals, law, custom, and other qualities acquired by man as a social being.

Language, therefore, expresses the patterns and structures of culture, and consequently influences human thinking, manners and judgement.

Four key components of culture have been identified in the sociological literature, namely, values, norms, institutions and artifacts (Hoult 1969). Values, which control other components of culture, deal with what a society attaches importance to; norms relate to patterns of behaviour designed for individual members of a society in particular situations; institutions relate to the divisions of a society where values and norms are applied; artifacts are objects that are produced from the values and norms of a culture. All these components are largely relativistic in nature, and they illuminate a society's systems, beliefs and worldviews

Proverbs deal with issues that border on the values, norms, institutions and artifacts of a society across the whole gamut of the people's experiences. Two examples of the way proverbs do this can be cited from the Yoruba culture:

Omo beere, osi beere.

Many children, much poverty

Bi oko ba moju aya tan, alarina a yeba

The moment a love relationship/marriage is intiated/contracted, the matchmaker steps aside.

The proverb in Example 1 touches on an aspect of the socio-economic values of the Yoruba. It simply suggests that having a few children, and by so doing, planning one's family, helps to rule out poverty. This proverb has proved particularly useful in the Southwestern Nigerian electronic media campaigns on family planning by non-governmental organizations and hospitals. In Example 2, the proverb reveals the practice in the marriage culture of the Yoruba, and specifies a norm that is associated with the institution. That the matchmaker's duty ends at the initiation of the relationship or contracting of the marriage implies that the Yoruba believe that no external influence is, or should be, allowed in the marital lives of couples. Proverbs thus become a tool to describe and express social, cultural, natural and other events/ practices. This point will be clearer in the next section where we attempt a discussion of popular and literary proverbs. 


\section{$3 \quad$ Popular and Literary Proverbs}

Given that proverbs are strictly context-dependent, it is essential to explore them in terms of how their meanings emerge in situations of use According to Firth (1926: 134):

The essential thing about a proverb is its meaning [...]. The meaning of a proverb is made clear only when side by side with the translation is given a full account of the accompanying social situation - the reason for its use, its effects, and its significance in speech.

Firth's point is that a clear meaning of a proverb can be appreciated when the social situation of its use is considered. Working within Firth's functional perspective and considering other structural variables, Yusuf and Methangwane (2003: 408) define proverbs as "relatively short expressions, which are usually associated with wisdom and are used to perform a variety of social functions". This is the definition that shall adopt in this paper.

Discussions of proverbs in the paremiological literature have often concerned their structures, types and functions. Proverbs in terms of structure show a quadripartite structure, a topiccomment pattern, are oppositional/non-oppositional and fixed in shape. They are also sometimes poetic or non-poetic in nature (Mieder 1989; Odebunmi 2006).

In terms of function, proverbs in Africa have been observed to "occur on all occasions when language is used for communication either as art or as tool [...] Proverbs are used in oratory, counselling, judging, embellishing speeches and enriching conversations" (Finnegan 1994: 36). Achebe (in Ogbaa 1981: 5) re-states these functions explicitly when he says:

A proverb is both a functional means of communication and also a very elegant and artistic performance itself [...]. So, when I use these forms in my novels, they both serve a utilitarian purpose; which is to re-enact the life of the people that I am describing and also delight through elegance and aptness of imagery.

The functions are projected through exploring the allusive, ironic and sarcastic potentials of proverbs (Odebunmi 2006).

Three types of American proverbs have been identified namely, legal proverbs, medical proverbs and weather proverbs (Mieder 1989). Much as these categories cut across the uses of proverbs in many cultures of the world, cultural differences and other situational factors often necessitate emergence of local categories. Some of these are the flora/fauna types Odebunmi (2006). A few more categories will be added in this paper as will be dictated by the intertextual functions of proverbs in The Gods.

Mieder (1974: 889) asks the following questions with reference to literary proverbs:

In what contexts do these proverbs appear?

How do they function in the popular piece of literature?

Which way do they offer new insights into the creative process of an author?

We shall address questions (i) and (ii) above in this paper: In what contexts do proverbs appear in The God, [and] how do they function in the text? Meanwhile, it is necessary to turn to the playwright himself, the rationale for the choice of the play and information about the text.

Ola Rotimi, who died in 2002, is an internationally acclaimed Nigerian playwright. He has written seven published plays to date, namely, Our Husband has gone Mad Again (1966/1974), The Gods are not to Blame (1971), Kurunmi (1971), Ovonramwen Nogbaisi (1974), Holding Talks (1979), If (1983) and Hopes of the Living Dead. The Gods has been selected in this paper because of the relative little attention paid to its linguistic analysis in general, and the analysis of its proverbs in particular. 
The Gods is a story of King Odewale who, at birth, is divined to kill his father, King Adetusa and marry his mother, Queen Ojuola. To avoid this unsavoury incident, Odewale is ordered to be killed in a grove. But Gbonka, the palace messenger detailed with this instruction, fails, out of pity for the barren Ogundele and Mobike, his wife, to kill the child; rather he hands the baby over to the barren couple to foster. When Odewale is fully grown up, the message of the gods are delivered to him again at Ijekun Yemoja. Mistaking his foster parents for his biological ones, Odewale runs away from 'home' to avoid the fulfillment of the prediction, only to achieve fame and royal feats at Kutuye, where he lives to fully act out the wills of the gods by marrying his mother, having inadvertently killed his father over a piece of land at Ede.

\section{The Theory of Pragmatic Acts}

This theory of pragmatic acts has been necessitated by the puncture made in the speech act theory especially as being best thought of atomistically (Fairclough 1989: 9) and non-situated (Mey 2001). This makes the speech act theory unsuitable for the analysis of proverbs in dramatic texts, as these proverbs can best be appreciated through a theory of action (Odebunmi 2006: 157). Therefore, our choice of pragmatic acts theory is expedient. Mey (2001) explains the concept of a pragmeme with the model below:
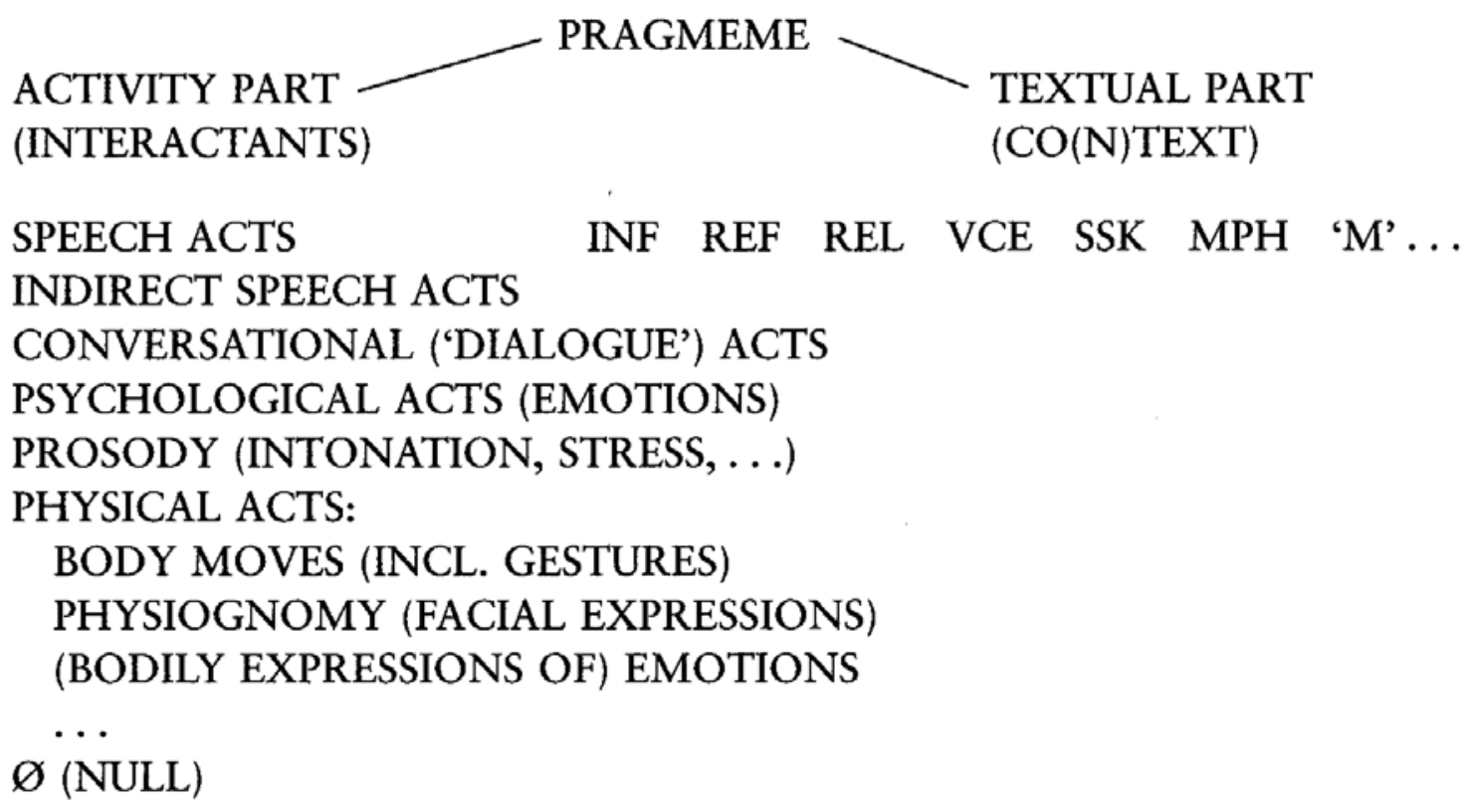

PRACT

ALLOPRACT

PRAGMEME, PRACT, ALLOPRACT

Figure 1: A Model of Pragmatic Acts (Mey 2001: 222)

In the words of Mey (2001: 221), the pragmatic act theory focuses on "the environment in which both speaker and hearer find their affordances, such that the entire situation is brought to bear on what can be said in the situation, as well as what is actually being said". This perspective is captured as a pragmeme, a generalized pragmatic act regarded as the only force associated with making utterances. 
A pragmatic act is instantiated through an ipra or a pract, which realizes a pragmeme. "Every pract is at the same time an allopract, that is to say a concrete instantiation of a particular pragmeme" (Mey 2001: 221). What determines a pract is solely participants' knowledge of interactional situation and the potential effect of a pract in a particular context. Thus, practing resolves the problem of telling illocutionary force from perlocutionary force.

Figure 1 shows that there are two parts to a pragmeme: activity part, meant for interactants and textual part, referring to the context within which the pragmeme operates). To communicate, the interactants draw on such speech act types as indirect speech acts, conversational ('dialogue') acts, psychological acts, prosodic acts and physical acts. These are engaged in contexts, which include INF representing "inference"; REF, "relevance"; VCE, "voice"; SSK, "shared situation knowledge"; MPH, "metaphor"; and M "metapragramatic joker". The interaction between activity part and textual part results in a pract or an allopract.

The metapragmatic joker points to particular metapragmatic activities. Central to it is "indexicality" which, at the pragmatic level, demands good knowledge of the context of the utterance made. Mey (2001) illustrates the metapragmatic nature of indexicality by exploring structural repetitions such as Biblical Pilate's "What I do, I do" (John 19: 22) and Bakhtin's (1994: 108), "Sentences are repeatable. Sentences are repeatable", whose meanings do not depend on the repetitions made, but rather on the indexical context. They point to particular persons who utter them and the conditions that necessitate their utterance. The indexicality here is implicit "and has to be brought out by an analysis of the discourse in which the utterance takes place" (Mey 2001: 199 [Hanks 1992]). Mey (ibid) further observes that the "implicit properties of the utterance reflect on the utterance itself, by indexing its user relation [italics his]: that is [...] they tell us something about how the utterance is produced, respectively received". He asserts that the metapragmatic indexicality plays a very vital role in understanding how pragmatic acts develop discourse. 


\section{Pragmatic Functions of Proverbs in The Gods Are Not to Blame}

Our analysis of crisis - motivated proverbs in The Gods shall be based on figure 2 below, which is a modified model of pragmatics presented by Mey (2001), and adapted by Odebunmi (2006).

\section{Proverbs}

S

CMP

NMP

$\mathrm{H}$

Social Political

Psychological acts context

REF, MPH

INF, SSK, SCK

REL

Practs:

counselling, cautioning

accusing, challenging,

veiling, persuading, prioritizing

enc ouraging, admitting,

threatening

Figure 2: A Modified Model of Pragmatic Acts in The Gods are not to Blame

Figure 2 shows that proverbs in The Gods are used between a speaker and a hearer, and are broadly divided into two: crisis motivated proverbs (CMP) and non-crisis motivated proverbs (NMP). NMP, which is not our focus in this paper, occurs in a relatively small number of occasions, when compared to CMP, the reason being that the events in the play are predominantly crisis-driven. Instances of NMPs are found where reference is made to the battle with Ikolu (p. 7), where Odewale is venerated (p. 7), where Baba Fakunle is praised (p. 26), where character assessment is made (p. 39) and where identity declaration and conflict are involved (pp. 42, 46, 51).

CMPs in The Gods bifurcate into social crisis-motivated proverbs (CMP: soc) and political crisis-motivated proverbs (CMP: Pol). Given that crises make a lot of demand on the psyche, all the instances of CMPs soc and CMPs pol are psychological acts, which interact with contextual features such as reference (REF), metaphor (MPH), inference (INF), shared situational knowledge (SSK), shared cultural knowledge (SCK) and relevance (REL) to produce the following practs: couselling, cautioning, accusing, challenging, veiling, persuading, prioritizing, encouraging, threatening and admitting. SCK was operationally introduced by Odebunmi (2006: 159) to be able to adequately account for the cultural factor in the use of proverbs. We discuss the practs as they relate to social and political crisis-motivated proverbs below. 


\section{Social Crisis-Motivated Proverbs}

The social crisis situations in The Gods, defined in terms of activities relating to day to day experiences of the Kutuje people including the people's encounter with nature, cover the outbreak of epidemics in Kutuje, divination/riddle of birth concerning Odewale and the contest between Odewale and King Adetusa, the former monarch of Kutuje. Although it bears some political colouration later in the play, the outbreak of epidemics in Kutuje, as seen at the actual point of occurrence is social as it is linked with the wrath of the gods, with no association with the political affairs of the community. But the contest between Odewale and King Adetusa is strictly social as it is over land, and not in any way, at least at the point of the contest, connected with the latter's throne. What is known to the two contesters at the instance is one trying to rob the other of his property. The proverbs used in these situations derive their sources from the faunal and flora resources of the Yoruba, their geography and their social structures. Driven by the exigencies of the situations already mentioned, the characters, using CMPs: soc counsel, accuse, challenge, persuade and encourage. In the dialogue between Odewale and the priest of Ifa in Act Three Scene3, we have the following utterances:
Voice:
You have a curse on you, son.
Odewale:
What kind of curse, Old one?
Voice:
You cannot run away from it, the gods have willed that you will kill your father, and then marry your mother!
Odewale:
Me! Kill my own father, and marry my own mother?
Voice:
It has been willed.
Odewale:
What must I do then not to carry out this will of the gods?
Voice:
'Nothing. To run away would be foolish. The snail may try, but it cannot cast off its shell. Just stay where you are.

By the proverb, "the snail may try, but it cannot cast off its shell", Voice co-textually works on his earlier statements: "You cannot run away from it, the gods have willed it [...]" and "it has been willed". He makes reference to the faunal resources of his environment, i.e. the snail and the shell of snail. The proverb rides on a metaphor. The interpretation is assisted by SCK, Odewale being a member of the culture i.e. Yoruba, in which the proverb exists, and SSK, given the circumstance necessitating the use of the proverb. All these are complemented by the relevance of the proverb to the question that stirs Odewale's mind. Odewale is thus, given all these contextual factors, able to draw appropriate inferences. To him, as projected in his proverbial response move:

Continue to stay in the house of my father and mother? Oh, no, the toad likes water but not when the water is boiling (p. 60)

his interpretation of the proverbial utterance of the Ifa priest that he should leave the environment completely to avoid the tragedy. What the priest of Ifa, with "the snail[...]", practs therefore is counseling: he has the fore knowledge of the danger lying ahead of Odewale and foresees him staying in his present environment as a probable solution. Other cases of counseling, using proverbs, are found on pages 14 and 60.

Many CMPs: soc are used to accuse. Examples abound on pages 9, 10 and 46. For example, when an epidemic breaks out in Kutuje, the townspeople gather at the palace to register their protest over their assumed non-caring attitude of Odewale. Some of their spokespersons speak in the following proverbial language: 


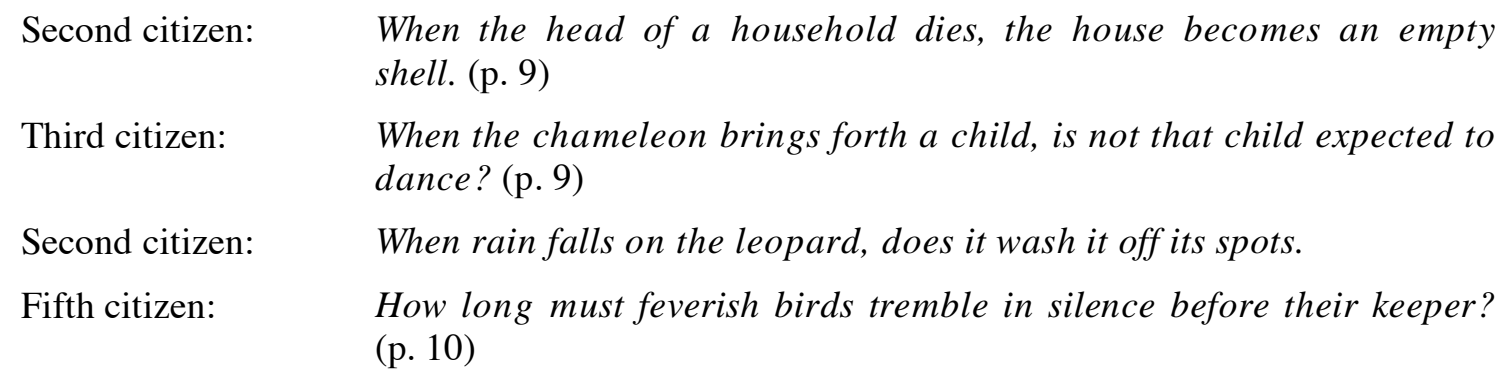

The proverbs largely derive from the fauna of the Yoruba. They make reference to the social structure of the Yoruba community, the genetic dancing skills of the chameleon, the permanent nature of the spots on the leopard and the relationship between birds and their keepers. Each of these demands SCK and SSK for it to appear as an accusation posed to Odewale for not being caring. In fact, in the proverbial utterance of Fifth Citizen, there is a subtle pract of challenging: "How long must feverish birds [...]", implicating that their seeming undue respect for the king might soon end if he continues to be insensitive to their plights.

In his response to the accusation of his people, Odewale, first, subtly persuades and, later, encourages, also using proverbs:

You do me great wrong, therefore to think that, like a rock in the middle of a lake, forever cooled by flowing waters, I do not know, and cannot know the sun's hotness that burns and dries up the open land. (p. 10)

Odewale refers to some geographical phenomena and atmospheric conditions in the Yoruba community i.e. a rock, a lake, the location of a rock in flowing waters, the hotness of the sun and its effect on the open land, the knowledge of all of which the audience are expected to share with Odewale. The proverb, which is a metaphor, states that the rock located in the middle of the lake experiences no hotness. The metaphor implies that Odewale sees his people as nursing the feeling that he luxuriates in the royal grandeur without devoting any attention to their degenerate conditions. What he practs, practically speaking, is explain his true position and role in the matter to them, contrary to their feeling. This point is further made in another proverb, performing the pragmatic function of persuading:

Have I been sleeping? If so, I am sick in the head: for only a madman would go to sleep with his roof on fire. (p. 11)

After he has convinced the people about the role he plays, he engages proverbs to encourage them to administer herbs properly and patiently. Two of these proverbs are important. The first appears in response to Third Woman's complaints:

Third woman: $\quad$ I boiled mine longer - a long time I even added dogoyaro leaves to it.

Odewale:

And how does the body feel?

Third woman:

Not as well as the heart wishes, my lord.

Odewale:

Our talk is of illness, sister. To get fully cured one needs patience.

The moon moves slowly but by daybreak it crosses the sky.

The proverb, "the moon [...]" reformulates, the co-textual expression: "[...] one needs patience". The clarity of the proverb is not in question, given the general social context, the co-text, SCK and SSK. Another pract of encouragement follows Fourth Woman's question: 
Fourth woman: $\quad$ My trouble is that I drink medicine from herbs, my husband drinks it too. But the children [...] I don't know how to give it to them so that they can drink it too.

Odewale: $\quad$ By trying often, the monkey learns to jump from tree to tree without falling.

Odewale evokes the SCK of Fourth Woman to link up the monkey's several attempts leading eventually to skillful acrobatics, with her own experience. This is not clearly reformulated but if SSK is appealed to in addition to SCK, no problem of interpretation would be expected.

\section{$7 \quad$ Political Crisis-Motivated Proverbs}

Political crisis-motivated proverbs in The Gods (describing activities that centre exclusively on the political affairs of the community, especially as related to problems surrounding Odewale's succession to the throne and the complications that attend the succession) are used during the following occasions: when Aderopo brings a message from Baba Fakunle; when the killer of King Adetusa is being sought; when the leaders of Kutuje have actual physical contact with Baba Fakunle; and after Baba Fakunle has left. These situations make the proverb user to draw on the social-cultural experiences of the people, their medical perspectives, their flora and their fauna. Practs of cautioning, threatening, accusing, veiling, prioritizing and admitting characterize the various exchanges.

The political crisis in the play begins with the message Aderopo brings from Baba Fakunle when sent to inquire about the cause of the epidemics in the land. The following transaction is very important in this regard:

Aderopo:

Second Chief:

Odewale:

Aderopo:

Odewale:

Aderopo:

Odewale and chiefs:

Ojuola:

Aderopo:
Very well. If a oracle says the curse, your highness is on a man.

A man!

And who is this man?

I don't know, your highness, the oracle did not say.

Very well. This man - the cursed one - what did he do, what offence?

The man killed another man [...] King Adetusa - my own father [...]

King Adetusa!

Who are we to trust, then?

That was why I feared to speak, mother. Until the rotten tooth is pulled out, the mouth must chew with caution.

(pp. 20-21)

Aderopo's proverb though immediately activated by Ojuola's question, "Who are we to trust?" is on the larger scale motivated by the political crisis on ground. The proverb is a medical one, which is pragmatically engaged to caution Odewale and the chiefs about the approach to use to identify the culprit.

Aderopo's message has obviously brought a riddle, which according to Odewale has to be loosened (p. 21). To do this, Odewale sees the need to be systematic. It is this need that necessitates his proverb:

Now my people, when trees fall on trees, first the topmost must be removed. (p. 22) 
Drawing on flora activities, he practs prioritization. This is reformulated and further clarified in his next statement: "First, tell me when was King Adetusa slain?" The trees falling on trees is a reference to the chronological sorting out and temporal location of the issues related to the situation at hand.

The crisis situation and expected political intrigues that follow cause participants to accuse each other of one offence or the other, using CMPs: pol. Examples of these proverbs can be found on pages 23, 30, 32, and 51. Two examples of such proverbs can be cited. After Aderopo has delivered Baba Fakunle's message, Odewale begins to dig into the cause of King Adetusa's death. In this bid, he suspects that the chiefs have a hand in the crime. He says:

Me an Ijekun man, a stranger in your tribe [stares at CHIEFS] when crocodiles eat their own egg, what will they not do to the flesh of a frog. (p. 23)

In this proverb, Odewale expresses the fear that he is not safe with the chiefs, reasoning that it is possible to trace the death of the former king to them. Invariably therefore, he implicitly accuses them of being responsible for the death of King Adetusa, and for possibly posing a threat to his own life as well, whose situation is even worse, being a non-native of Kutuje. The same pract is performed in

The hyena flirts with the hen, the hen is happy, not knowing that her death has come. (p. 30)

Also, proverbs, which accuse are used in the interaction between Odewale and Aderopo in Act Two, scene 2:

If you think you can drum for my downfall, and hope that, drum will sound, then your head is not good. (p. 32)

The proverb exploits the knowledge of the socio-cultural functions drums are made to perform in the Yoruba community. By this proverb, Odewale accuses Aderopo of plotting against him. This is clearly stated in his next non-proverbial statement:

If you think like a tortoise you can plot against me without my first cutting you down with my own tortoise tricks, then, fellow, madness is in your liver. (p. 32)

It is these accusations together with the dysphemisms: "your head is not good" and "madness is in your liver" that prompt Aderopo's rudeness to Odewale, equally expressed with a dysphemism:

Your highness, if you think to have heavy suspicion is wisdom, then your head is not well. (p. 32)

The situation degenerates into serious verbal combats between the two, leading to Odewale's threat to banish Aderopo from Kutuje, for he sees him as a dangerous contender. This is expressed in the proverb:

Two rams cannot drink in the same bucket at the same time. They will lock horns. (p. 34)

By this proverb, Odewale threatens Aderopo, who is presented as the ram that tugs his throne with him. Engaging SCK and SSK, Aderopo makes appropriate inferences from this proverb, and reaches Odewale's intended meaning. He asks: "Who is stopping you from being king?" (p. 35). It is this question that now prompts a plain, non-proverbial expression of Odewale's meaning:

You [...] trying to. Your intrigues, and blackmail and[...] Ooh! Take your time, child. (p. 35)

But he ends this with another threat practing proverb:

[...] If you rise too early the dew of life will soak you. (p. 35) 
Another pract that is associated with CMPs: pol is that of veiling. Two instances of this can be cited.

Odewale: Details, son, give us the details.

Aderopo: $\quad$ I'd rather tell you those in private my lord.

Odewale: Private! What is private about a whole kingdom in pain?

Aderopo: $\quad$ It is said that the secrets of a home should be know first to the head of the home.

Odewale: $\quad$ I refuse to listen alone. Speak openly son before all - a cooking pot for the chameleon is a cooking pot for the lizard.

This scene is where Aderopo comes fresh with the unsavoury message from Baba Fakunle, which he feels should not be announced publicly at that moment. He draws on the proverb "the secrets of [...]." equalling Odewale with that head who deserves a foreknowledge of the news. Odewale refuses to co-operate with Aderopo, countering with another proverb, "a cooking pot.." with which he declares that no privacy is warranted as far as the present situation is concerned. In fact, he means to say, though rather wrongly given the social structure of the Yoruba community, that all of the people present are equal, which removes need for a preferential treatment, as offered by Aderopo. By Aderopo's act, he is veiling the news to honour Odewale, as the king and head of the community.

Veiling is also employed in another proverb. After Alaka has declared that Ogundele and Mobike are Odewale's foster parents, Odewale insists on knowing his root:

Odewale: $\quad$ Hunter Ogundele is not my father; his wife Mobike is not my mother. You said so. Well, who gave me life?

Alaka:

It is well, I will tell you [...] but [...] I beg you let us go inside, you and I alone, in private. Secrets of the owl must not be known in the daylight.

Alaka's proverb unlike that of Aderopo is not meant to honour Odewale, but rather to conceal the truth, which he feels would stigmatize Odewale. However, while Odewale recognizes his intention, he does not subscribe to his offer rather he opts for Alaka proving publicly that he is "indeed without father and mother" (p. 62).

Finally, after the truth of Odewale's parentage has been revealed, he gouges out his own eyes and asks his children to lead him out of the town, serving the punishment he earlier pronounced on the culprit. When chiefs rush to stop him, he utters a CMP: Pol:

When the wood-insect gathers sticks, on its own head it carries them.

Odewale, through the proverb, refers to the wood-insect, which carries its burden by itself. He expects, working on SSK, his audience to understand that he admits responsibility for the crime committed and is ready to face the appropriate music.

\section{Conclusion}

By and large, we have shown that two types of crisis - motivated proverbs characterize The Gods, namely, social crisis-motivated proverbs and political crisis-motivated proverbs. The social ones are situated in the events of the outbreak of epidemics in Kutuje, divination/riddle of birth concerning Odewale and the contest between Odewale and King Adetusa over a piece of land in Ede. These proverbs are sourced from the flora and faunal 
resources of the Yoruba, their geography (and atmospheric conditions) and their social structures. The political ones are found in scenes where Aderopo brings a message from Baba Fakunle, where the killer(s) of King Adetusa is sought, and where Baba Fakunle makes physical presence (and when he has departed).

Given the relatively little attention paid to the use of proverbs in The Gods, the work has contributed significantly to the paremiological literature. It has also provided useful information that could assist in language teaching. The classification of proverbs into CMP: soc and CMP: pol, for example, can be used as a guide to explain related proverbs. Also, further context-derived classifications can be made, using insights provided in this paper. The events corresponding with the proverbs and the non-proverbial reformulations of the proverbs in the play can also be exploited both as interpretations and demonstrations of the meanings of the proverbs. Future research can concentrate on how the non-crisis-motivated proverbs in the play contribute to the development of the theme(s) and plot of the text.

\section{References}

Bakhtin, Mikhali (1986/1994): Speech Genres and Other Late Essays (trans. Vern W. Mc Gee). Austin.

Fairclough, Norman (1989): Language and Power. London.

Finnegan, Ruth (1994): "Proverbs in Africa". In: Mieder, Wolfgang/Dundes, Alan (eds.): The Wisdom of many. Essays on the Proverb. London: 10-42.

Firth, John (1926): "Proverbs in Native Life with Special Reference to those of Maori". Folklore 37: 134-153.

Green, E./Korobo-Solomon, F. (2002): "Aspects of Traditional region in Ola Rotimi's 'The Gods are not to Blame'". Journal of Religion and Culture 3, 1 \& 2: 33-38.

Hanks, William (1992): "The Indexical Ground of Deictic Reference". In: Duranti, Alessandre/Goodwin, Charles (eds.): Rethinking Context. Language as an Interactive Phenomenon. Cambridge: 43-76.

Hoult, Thomas (ed.) (1969): Dictionary of Modern Sociology. New Jersey.

Khadka, Netra (2006): "Culture. A Dynamic Process of Social Behaviour". International Journal: Language, Society and Culture. http://www.educ.utas.edu.au/users/tle/ JOURNAL/Articles/Khadka/Khadka2.html (accessed August 29, 2007).

Leigh, James/Stanbridge, David (1991): Multicultural Communication. Nicosia.

Mey, Jacob (2001): Pragmatics. An Introduction. Oxford.

Mieder, Wolfgang (1974): "The Essence of Literary Proverbs". Proverbium 14: 379-383.

Mieder, Wolfgang (1989): "American Proverbs. A Study of Texts and Contexts". Sprichwörterforschung 13: 195-221.

Monye, Ambrose (1995): "The Use of Proverbs in Ola Rotimi's 'The Gods are not to Blame'". Proverbium 12: 251-262.

Odebunmi, Akin (2006): "A Pragmatic Reading of Yerima's Proverbs in 'Yemoja Attahiru' and 'Dry Leaves on Ukan Trees'". Intercultural Pragmatics 3, 2: 153-170.

Ogbaa, Kalu (1981): "Interview with Chinua Achebe". Research in African Literatures 12, 1: 1-13.

Ogbulogo, Charles (2002): "Proverb as Discourse. The Example of Igbo Youth and Culture Heritage". Journal of Cultural Studies 4, 1: 37-49.

Oloruntoba-Oja, Taiwo (1998): Language and Style in Nigerian Drama and Theatre. Ibadan.

Rotimi, Ola (2000): The Gods are not to Blame. Ibadan.

Yusuf, Yisa/Methangwane, Joyce (2003): "Proverbs and HIV/AIDS. Proverbium 20: 407422. 